\title{
DEVELOPMENT OF REACTOR POWER CONTROL LOGIC FOR THE POWER MANEUVERING OF KALIMER-600
}

\author{
SEUNG-HWAN SEONG*, HAN-OK KANG and SEONG-O KIM \\ Korea Atomic Energy Research Institute, 1045 Daedeokdaero, \\ Yuseon-gu, Daejeon, 305-353, Rep. of KOREA \\ *Corresponding author. E-mail : shseong@kaeri.re.kr \\ Received November 19, 2009 \\ Accepted for Publication May 01, 2010
}

\begin{abstract}
We developed an achievable control logic for the reactor power level during a power maneuvering event and set up some constraints for the control of the reactor power in a conceptual sodium-cooled fast reactor (KALIMER-600) that was developed at KAERI. For simulating the dynamic behaviors of the plant, we developed a fast-running performance analysis code. Through various simulations of the power maneuvering event, we evaluated some suggested control logic for the reactor power and found an achievable control logic. The objective of the control logic is to search for the position of the control rods that would keep the average temperature of the primary pool constant and, concurrently, minimize the power deviation between the reactor and the BOP cycle during the power maneuvering. In addition, the flow rates of the primary pool and the intermediate loop should be changed according to the power level in order to not violate the constraints set up in this study. Also, we evaluated some movement speeds of the control rods and found that a fast movement of the control rods might cause the power to fluctuate during the power maneuvering event. We suggested a reasonable movement speed of the control rods for the developed control logic.
\end{abstract}

KEYWORDS : Sodium-cooled Fast Reactor; KALIMER-600; Power Control Logic; Power Maneuvering Event

\section{INTRODUCTION}

A conceptual Korea Advanced LIquid Metal Reactor600MWe (KALIMER 600) was developed at the Korea Atomic Energy Research Institute (KAERI). It is a pooltype fast reactor that uses sodium as the coolant in the primary pool and the intermediate loop [1]. In this study, we developed a reactor power control logic for the power maneuvering event of the plant. In order to develop the control logic, a performance analysis code is required. However, the currently available performance analyzers based on the pressurized water reactor were not able to easily solve the thermodynamic behavior of the KALIMER600. Therefore, we developed a fast-running performance analysis code for the KALIMER-600 in a previous study[2]. The code adopted a commercial Modular Modeling System (MMS) code as the base solver for the governing equations of the system. The MMS code has lots of modules, such as a PID controller, pipe, pipehx, valve, pump, turbine and fuel (core) modules that can be connected to one another in order to analyze the integral thermodynamic behavior of the plant[2,3]. Similar to other codes, the MMS code does not have any material library of sodium and the thermodynamic correlations to analyze the KALIMER-600. In a previous study, we developed a library for the properties of sodium and then attached it to the MMS code [4]. Moreover, we modified some modules, such as the fuel, pipe, and pipehx to be suitable for analyzing the thermodynamic behaviors of the KALIMER-600 with the superheated Rankine cycle [2-6].

Using the developed performance analysis code, we studied the control logic for the reactor power when the Balance Of Plant (BOP) power changed. We targeted the control system to be able to afford a step change of $10 \%$ and a ramp change of $5 \% / \mathrm{min}$ for the reactor power. In addition, we set up some constraints for the reactor power control logic in order to ensure the safety and performance of the KALIMER-600. The cold pool temperature should be lower than the creep condition of the reactor vessel and, in addition, the average temperature of the coolant should be kept constant in order to minimize the changes of the reactivity in the core from the temperature feedback and to maintain the volume of the primary pool during the power maneuvering. With these constraints, we developed a reactor power control logic and found the most suitable movement speed and position of the control rod during the power maneuvering event. After further studies with various performance-related events, we will optimize the reactor power control logic for the KALIMER-600. 


\section{CHARACTERISTICS OF REACTOR POWER CONTROL LOGIC FOR KALIMER-600}

\subsection{Features of KALIMER-600}

The KALIMER-600 is a pool-type sodium-cooled fast reactor and has two heat transport systems: a primary pool, and an intermediate loop [1]. The core heat in the primary pool is transferred to the intermediate loop by way of the intermediate heat exchangers and then transferred to the BOP cycle through the steam generators. The core uses metal fuel assemblies where its thermal power is 1523.4MW. The hot and cold temperatures in the primary pool are $545^{\circ} \mathrm{C}$ and $390^{\circ} \mathrm{C}$, respectively. The pressure of the cover gas region in the primary pool is about 0.1 $\mathrm{MPa}$. The temperatures of the hot leg and cold leg in the intermediate loop are $526^{\circ} \mathrm{C}$ and $320^{\circ} \mathrm{C}$ The flow rates of the primary pool and the intermediate loop are $7731.3 \mathrm{~kg} / \mathrm{s}$

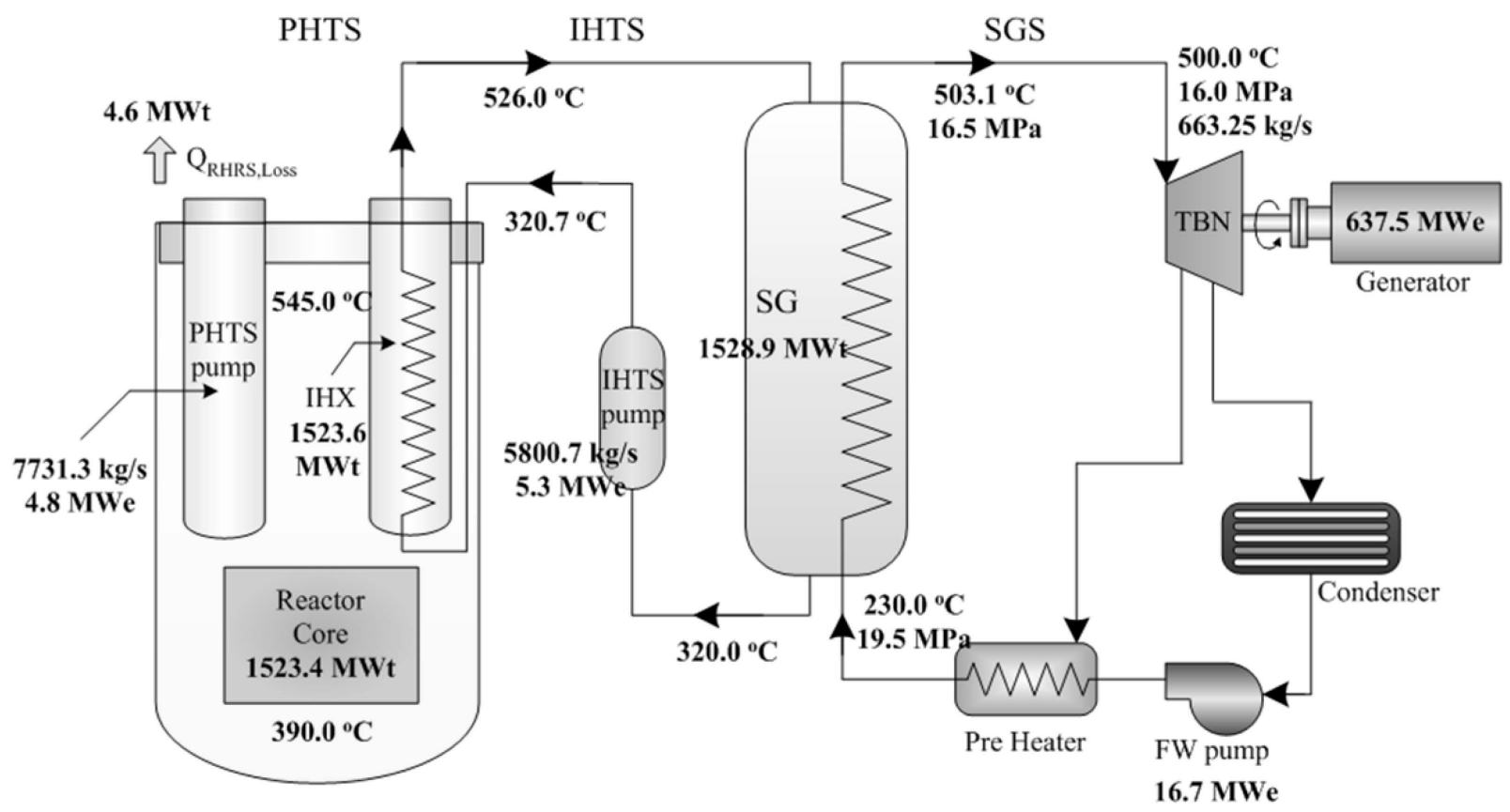

Fig. 1. Heat Balance of KALIMER-600

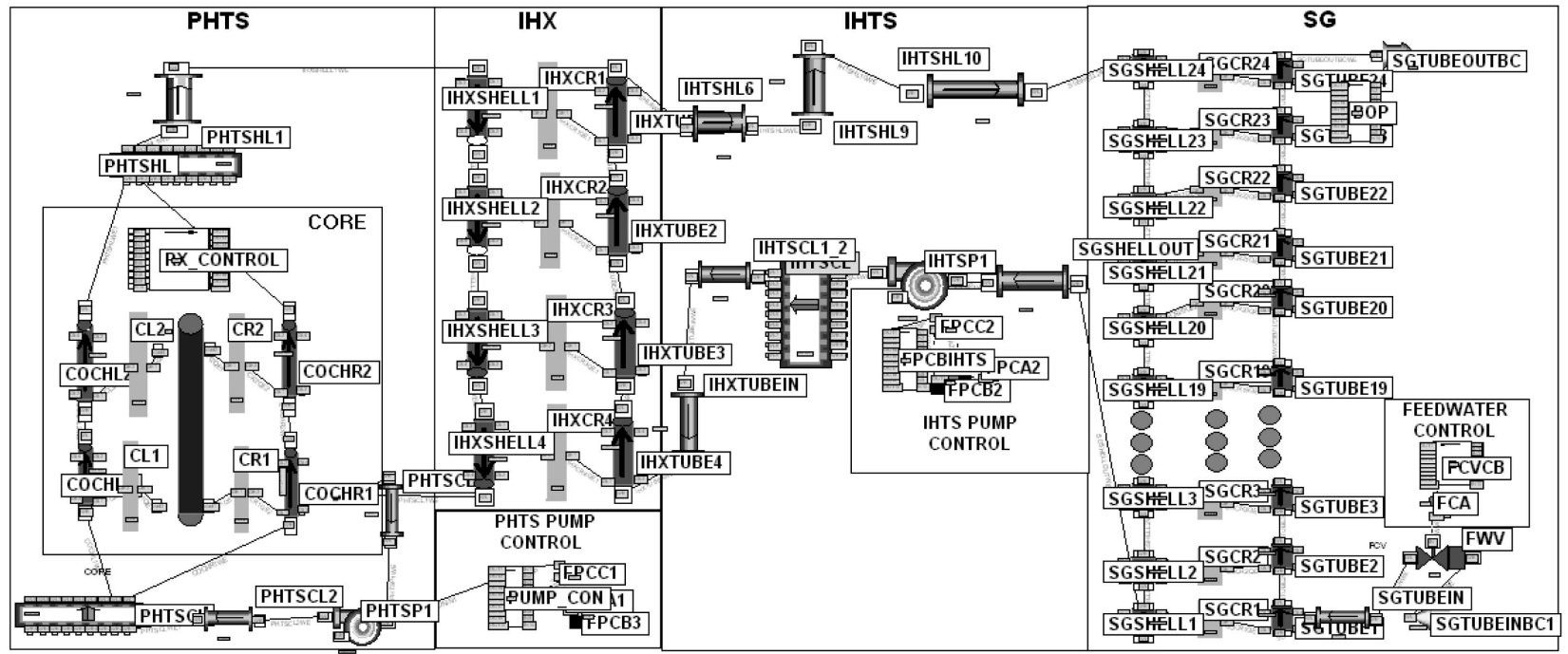

Fig. 2. The Analysis Model of MMS-LMR-SG Code 
and $5800.7 \mathrm{~kg} / \mathrm{s}$. The net electric power is $600 \mathrm{MW}$ and the flow rate of the feedwater is $663.25 \mathrm{~kg} / \mathrm{s}$ at a nominal condition. Figure 1 shows the heat balance of the KALIMER600 at the rated full power condition while detailed data for KALIMER-600 are described in Reference 1.

\subsection{Development of a Performance Analysis Code}

In order to develop the reactor power control logic, a performance analysis code that can evaluate the transient behavior of the plant and the reactor is required. We adopted the MMS code as a solver for the governing equations of the plant $[2,4]$. The MMS uses a lot of software modules that can represent the plant's components, such as pipe, pump, pipehx, turbine and fuel (core) modules, and those modules can be connected to each other in order to analyze the transient behavior of the plant. Also, the MMS code has some control components, such as a PID control module, that can express a controlled action. These control components can be used to analyze the dynamic behavior of a plant in real time according to the control actions. Therefore, we adopted the MMS as a flow and energy solver in order to develop a fast-running performance analysis code for the KALIMER-600. We modified some software modules to be adequate enough to the components of the KALIMER-600 and we built a new material property library, including sodium $[2,3,4]$. Also, we modified the Doppler model and the feedback model of the coolant temperature in the core in order to simulate the core dynamics of the KALIMER-600. In addition, we implemented some heat transfer models in the MMS code that would simulate the heat exchangers of the KALIMER-600 [5].

Since the BOP cycle has not been yet designed in detail, we considered the feedwater system and the superheated steam system as the boundary conditions. The pressure of the steam system, as well as the temperature and pressure of the feedwater were assumed to be constant under any operational conditions [6,7]. Figure 2 shows

Table 1. Summary of Steady State Calculation

\begin{tabular}{l|c|c|c}
\hline Parameters & reference & result & Error $(\%)$ \\
\hline Reactor Power $[\mathrm{MW}]$ & 1523.4 & 1521.6 & 0.11 \\
\hline $\begin{array}{l}\text { Temperature at core } \\
\text { inlet/outlet }\left[{ }^{\circ} \mathrm{C}\right]\end{array}$ & $390 / 545$ & $389.8 / 544.9$ & $0.05 / 0.02$ \\
\hline PHTS flow rate $[\mathrm{kg} / \mathrm{s}]$ & 7731.3 & 7731.0 & 0.004 \\
\hline $\begin{array}{l}\text { Temperature at IHX } \\
\text { inlet/outlet in IHTS }\left[{ }^{\circ} \mathrm{C}\right]\end{array}$ & $320.7 / 526.0$ & $320.3 / 525.8$ & $0.12 / 0.04$ \\
\hline IHTS flow rate $[\mathrm{kg} / \mathrm{s}]$ & 5800.7 & 5812.1 & 0.20 \\
\hline Steam Temperature $\left[{ }^{\circ} \mathrm{C}\right]$ & 503.1 & 504.0 & 0.18 \\
\hline Steam flow rate $[\mathrm{kg} / \mathrm{s}]$ & 663.25 & 662.4 & 0.13 \\
\hline
\end{tabular}

the schematic diagram of the developed performance analysis code. We assumed the heat transfer rate through the steam generator was equal to the BOP power. In other words, the BOP power could be obtained by calculating the heat transfer rate through the steam generator in the performance analysis code by changing the flow rate of the feedwater.

In order to evaluate the accuracy of the model, including the geometric data and thermodynamic properties of the coolant with the flow rate, as well as the distributions of the temperature in the loops, the steady state of the KALIMER-600 was analyzed and verified with the design data. The detailed geometric and thermodynamic data for the steady state analysis are given in Reference 1. Table 1 shows the results of the steady state calculation for a rated full power operational condition.

\subsection{Constraints for the Reactor Power Control Logic}

In order to develop the control logic of the reactor power control, we set up some constraints that would ensure the safety and performance of the KALIMER600. Since the KALIMER-600 operates in very high temperatures under low pressure, the temperature distribution should be considered one of the constraints. The temperature in the cold pool should be kept less than about $420^{\circ} \mathrm{C}$ during plant operation in order to not violate the creep condition of the stainless steel used in the reactor vessel. Also, the temperature increase through the core should be kept as constant as possible in order to mitigate the impact on the structural integrity of the core during the power maneuvering.

In addition, we supposed that the operation of the constant average temperature in the primary pool as one of the constraints in order to minimize the change in the volume of the primary pool and the reactivity of the core resulting from a change in the coolant temperature. The flow rates of the primary pool and the intermediate should be above $50 \%$ of the rated full operation conditions in order to eliminate the possibility of thermal stratification in the primary pool and the intermediate loop of the plant. We considered that the pressure distribution was not a constraint because the reactor was operating under a very low pressure condition (about $0.1 \mathrm{MPa}$ ) and the averaged temperature in the primary pool was considered to be constant during operation.

\section{DEVELOPMENT OF REACTOR POWER CONTROL LOGIC}

In the reactor power control logic, the controlled variables are the temperature of the coolant and the reactor power level. The controllable variables are not only the flow rates of the primary pool and the intermediate loop but also the movement speed, and the position of the control rods. We developed the reactor power control 


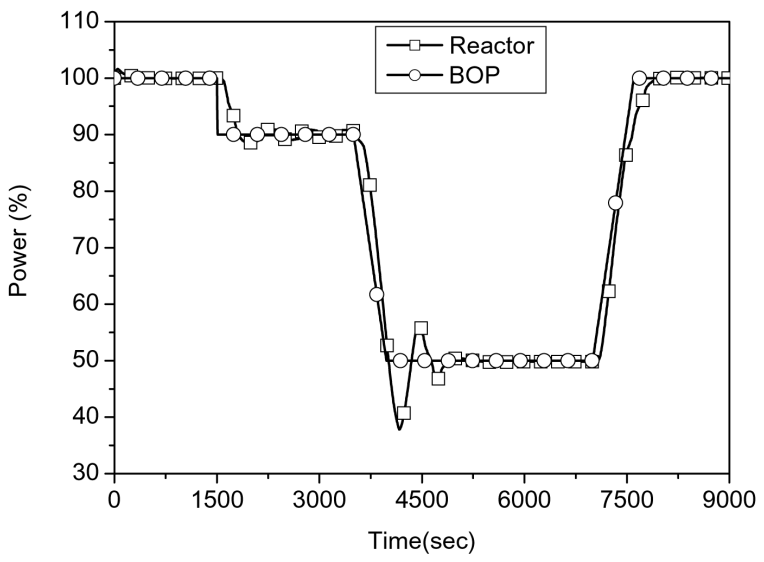

(a) power

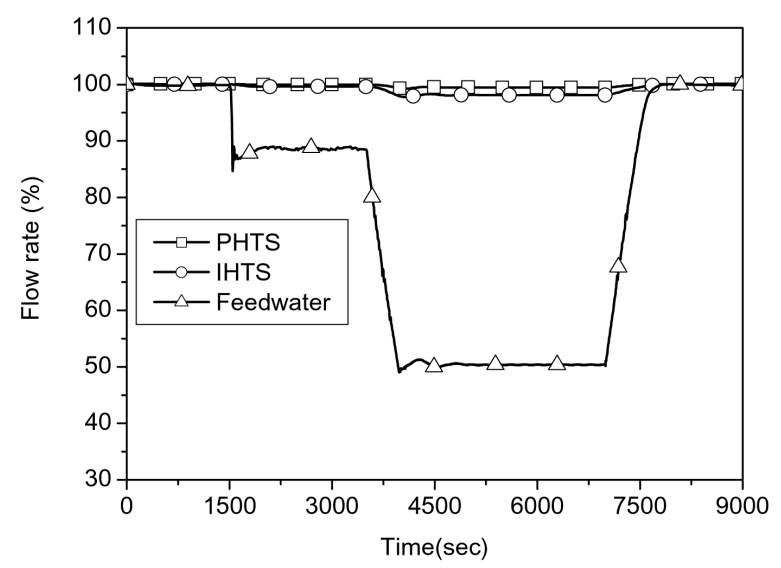

(c) flow rate

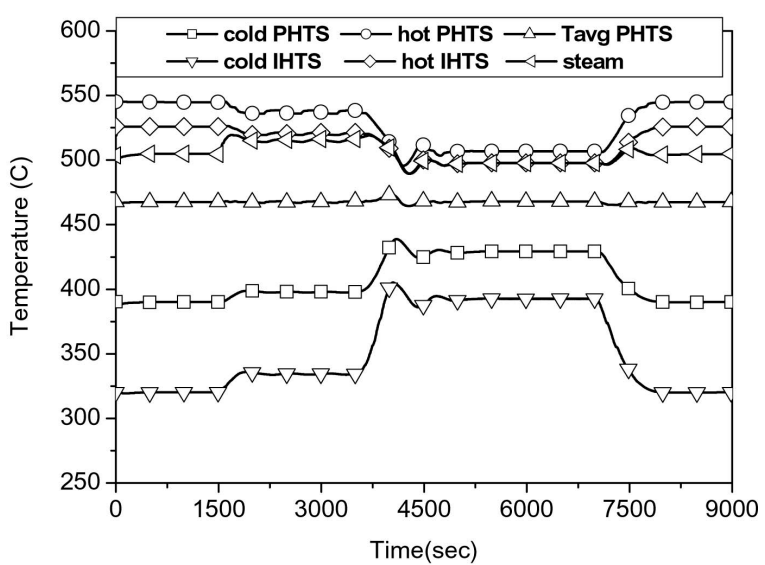

(b) temperature

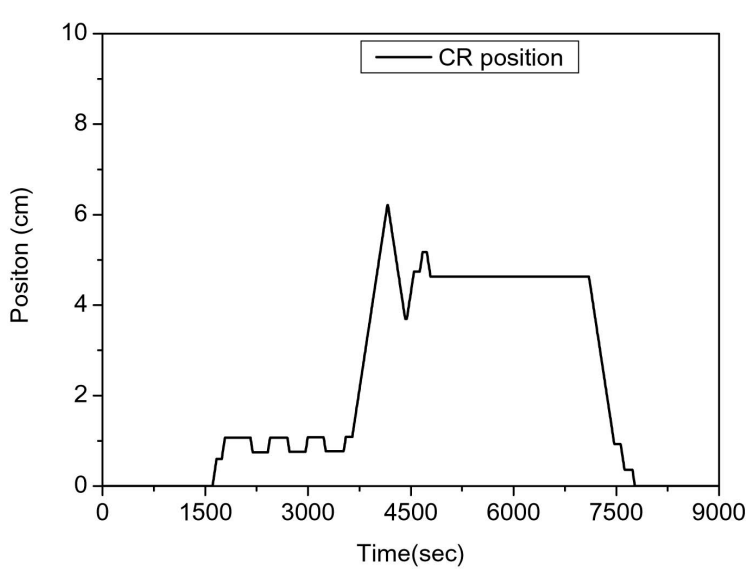

(d) control rod position

Fig. 3. Simulation Results of Case 1

Table 2. Summary of Analysis Cases

\begin{tabular}{c|c|c|c}
\hline Cases & Control object & PHTS/IHTS flow & CR speed $(\mathrm{cm} / \mathrm{sec})$ \\
\hline 1 & $\mathrm{~T}^{1)}$ & Fixed & 0.01 \\
\hline 2 & $\mathrm{~T}$ & Reactor variable $^{4)}$ & 0.01 \\
\hline 3 & $\mathrm{~T}$ & BOP variable & 0.01 \\
\hline 4 & $\mathrm{~N}^{2)}$ & BOP variable & 0.01 \\
\hline 5 & $\mathrm{~T}^{2} \mathrm{~N}^{3)}$ & BOP variable & 0.01 \\
\hline 6 & $\mathrm{~T}+\mathrm{N}$ & BOP variable & 0.025 \\
\hline 7 & $\mathrm{~T}+\mathrm{N}$ & BOP variable & 0.035 \\
\hline
\end{tabular}

1) constant Tavg of PHTS

2) power deviation of reactor and BOP power

3) concurrent control of $\mathrm{T}$ and $\mathrm{N}$

4) variable flow rates of PHTS/IHTS with reactor power

5) variable flow rates of PHTS/IHTS with BOP power logic with the constraints set up in this study and simulated the plant parameters through the analyses of a power maneuvering operation of 100-90-50-100\% of the rated full power.

In these simulations, the BOP power was kept as a full-rated power for $1500 \mathrm{sec}$ in order to build a steady state. Then, the BOP power was suddenly dropped to $90 \%$, which was maintained to $3500 \mathrm{sec}$ in order to evaluate the capability of the control logic for a $10 \%$ step change of the reactor power. After that, the BOP power was decreased to $50 \%$ with a ramp rate of $5 \% / \mathrm{min}$, which was kept until $7000 \mathrm{sec}$. Finally, the BOP power was recovered up to $100 \%$ with the same ramp rate and maintained to the end of analysis. We assumed that the heat transfer rate through the steam generator could emulate the BOP power due to the lack of a detailed design of the BOP cycle. The heat transfer rate could be manipulated by changing the flow rate of the feedwater, where its flow rate was adjusted by the feedwater control valve $[6,7,8]$. Also, we assumed a 


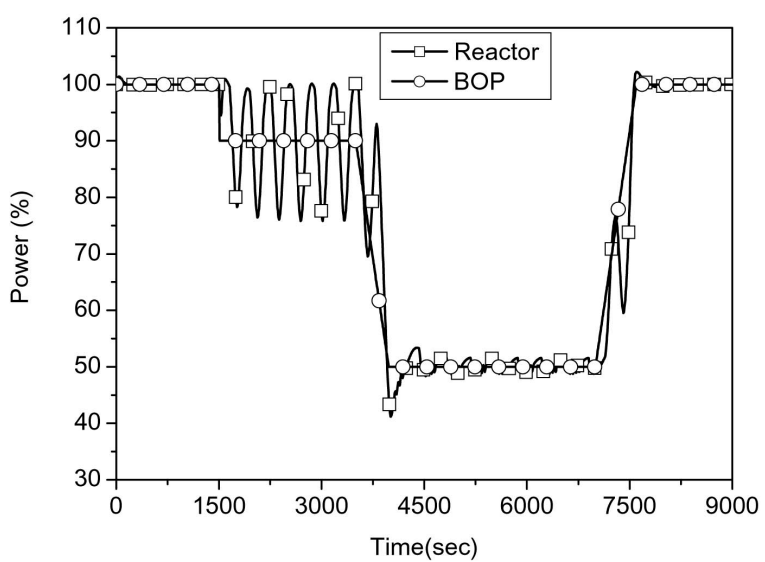

(a) power

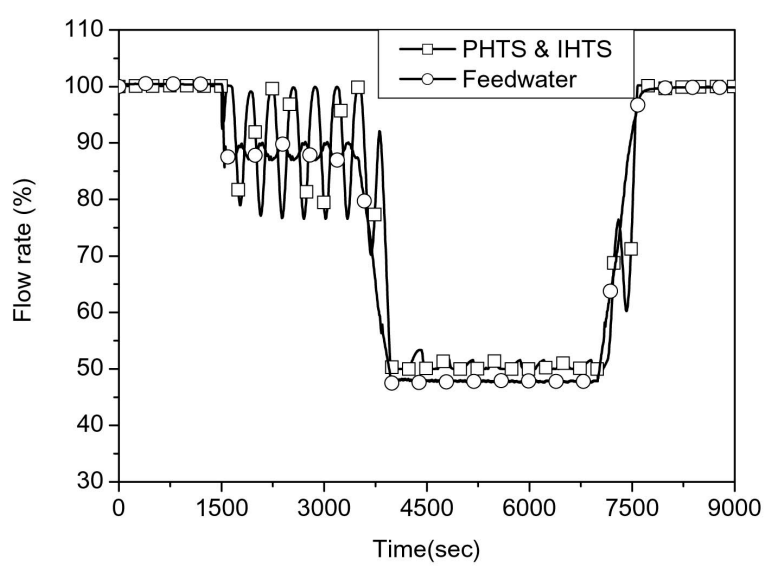

(c) flow rate

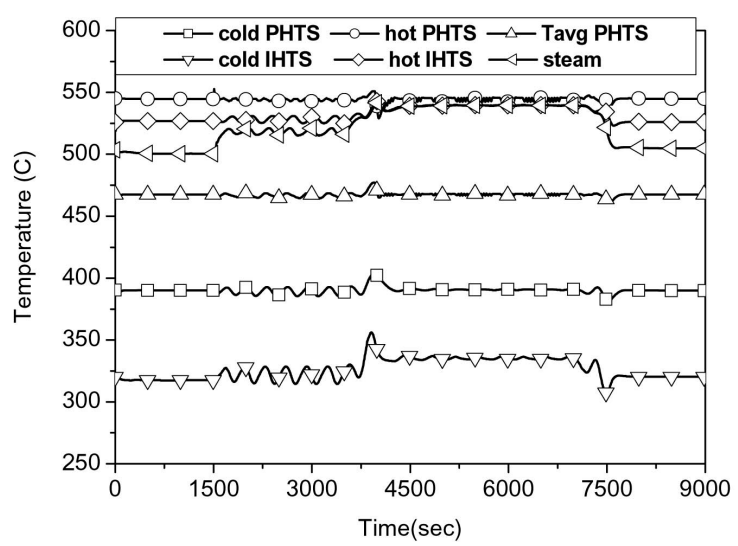

(b) temperature

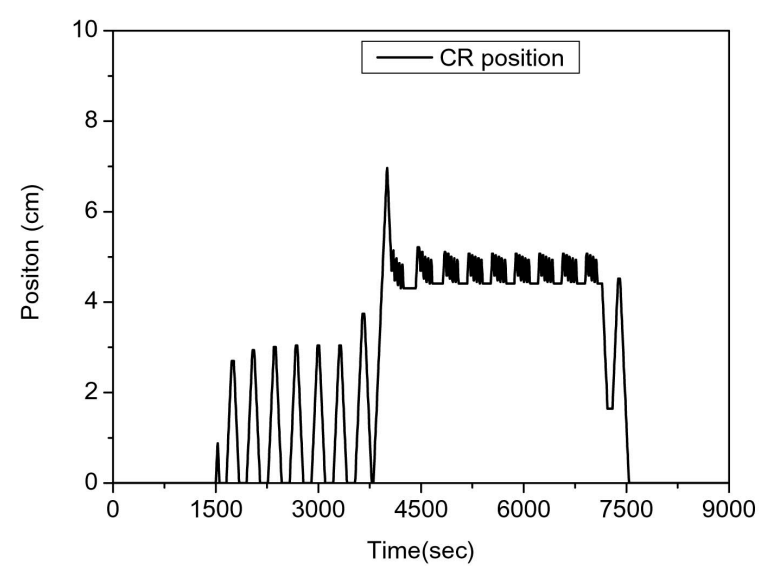

(d) control rod position

Fig. 4. Simulation Results of Case 2

constant steam pressure, as well as a constant temperature and pressure of the feedwater by assuming some ideal controllers in the steam and feedwater system. With these assumptions, we studied some control logics for the reactor power following the BOP power. Table 2 shows the summary of the analysis cases.

First, we simulated the control logic of keeping the average temperature (Tavg) in the primary pool constant. The position of the control rods was adjusted in order to keep the average temperature of the primary pool constant and to compensate for the reactivity change induced from the changes in the BOP power during the power maneuvering event. Figure 3 shows the simulation results of Case 1. As shown in Figure 3, the reactor power well followed the BOP power, and the average temperature of the primary pool was kept constant. However, the temperature in the cold pool was increased to about $430^{\circ} \mathrm{C}$ at a $50 \%$ power level. Therefore, this logic is not acceptable for the power maneuvering of the KALIMER-600 because the cold temperature can threaten the integrity of the reactor vessel, as described in Section 2.3. In the first case, we did not change the flow rates of the primary pool (Primary Heat Transfer System: PHTS) and the intermediate loop (Intermediate Heat Transfer System: IHTS) and only controlled the position of the control rods in the core.

Secondly, we simulated the power maneuvering event with the same control logic for the reactor power, but we changed the flow rates of the primary pool and the intermediate loop according to the level of the reactor power $[7,8,9]$. The ratio of the flow rates was assumed to be the same as the level of the reactor power, but the lowest ratio during any operation should not be less than $50 \%$ by the constraints mentioned in Section 2.3. In order to change the flow rate in the primary pool and the intermediate loop, we implemented feedback controllers for adjusting the pump speed without any valves in order to eliminate the probability of a sodium leak.

Figure 4 shows the simulation results of Case 2. Unlike 
the previous simulation, the reactor power fluctuated during the power maneuvering, although the average temperature of the primary pool was kept constant. The reasons of this fluctuation are the following. The flow rate of the feedwater was first adjusted in order to meet the BOP power during the power maneuvering. Then, the adjusted flow rate of the feedwater changed the outlet temperature at the shell side of the steam generator. This temperature change in the intermediate loop caused a change of temperature in the cold pool of the primary pool after some delay, which originated from the circulation time of the coolant in both the primary pool and intermediate loop. After that, the reactor power followed the BOP power by the reactivity feedback mechanism and the control logic for the reactor power.

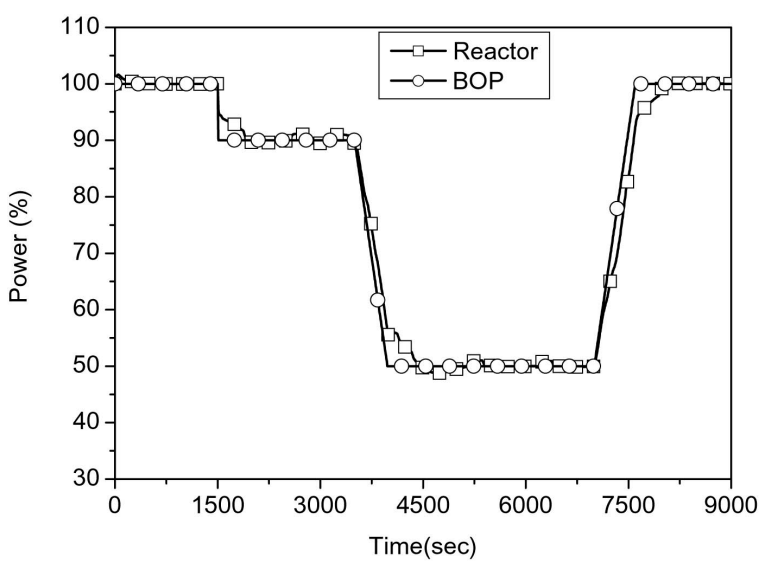

(a) power

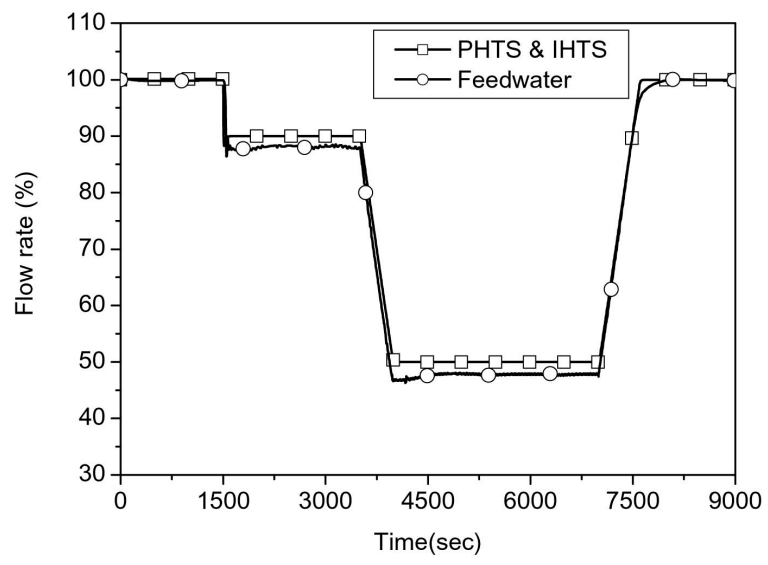

(c) flow rate
Then, the flow rates of the primary pool and the intermediate loop were changed again according to the power level of the reactor. In this process, there was a significant time lag between the movement of the control rods in adjusting the reactor power and the effect of the change in the flow rates. The control rods moved promptly within a second, but the effect of the change of the flow rates occurred after some delay that originated from the circulation time of the coolants in the primary pool and the intermediate loop. This time lag made the power level fluctuate.

We introduced a modified logic for controlling the flow rates in order to minimize the fluctuation of the reactor power during the power maneuvering. During the power maneuvering event, the reactor power should

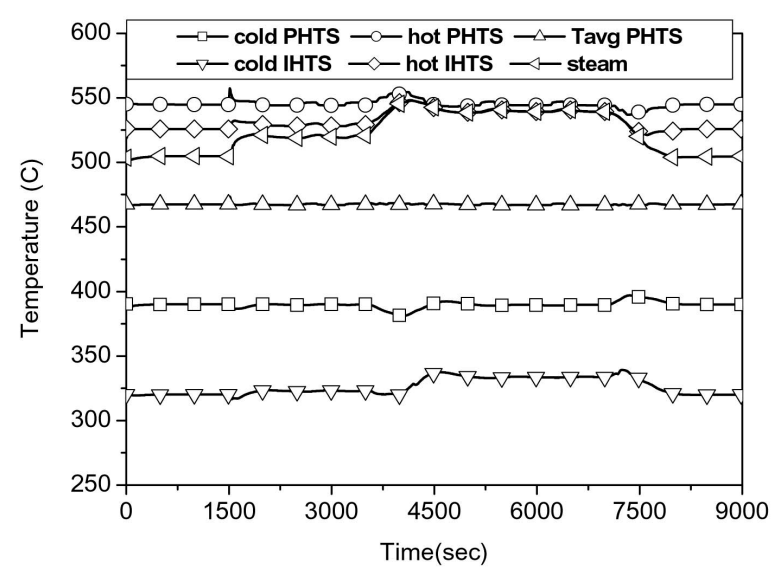

(b) temperature

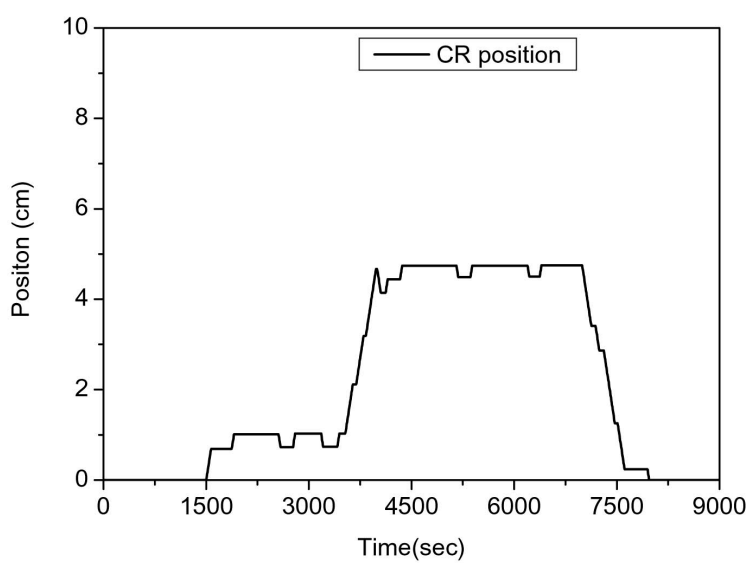

(d) control rod position

Fig. 5. Simulation Results of Case 3 
asymptotically follow the BOP power where the BOP power might have been assumed to be more stable because it is a target value dispatched from the external electricity needs. Therefore, we deduced that both flow rates would not follow the reactor power, but the BOP power. This logic was able to minimize the time lag between the change in the reactor power and the BOP power because both flow rates could be adjusted in advance before the reactor power was stabilized during the power maneuvering. With the same control logic for the rector power and the modified control logic for the flow rates, we simulated the power maneuvering event. Figure 5 shows the results. With this logic, we found that the fluctuation of the reactor power could be minimized where the reactor power asymptotically followed the BOP power.

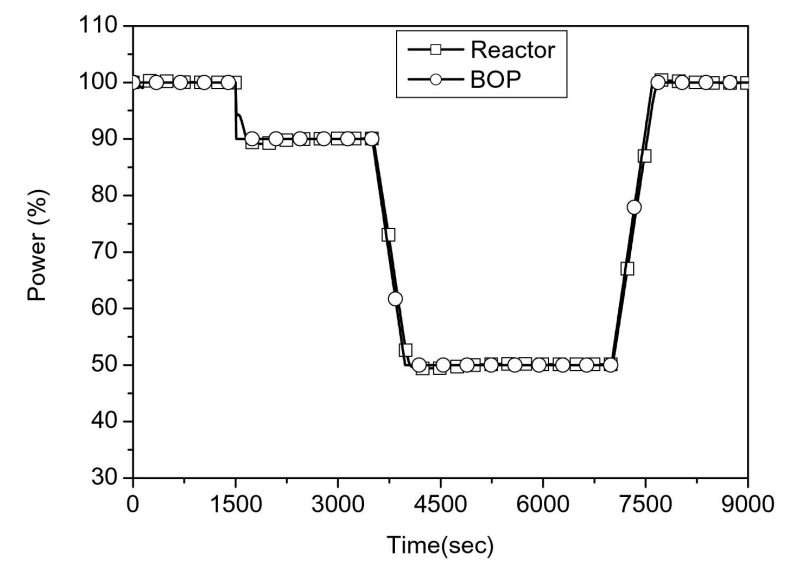

(a) power

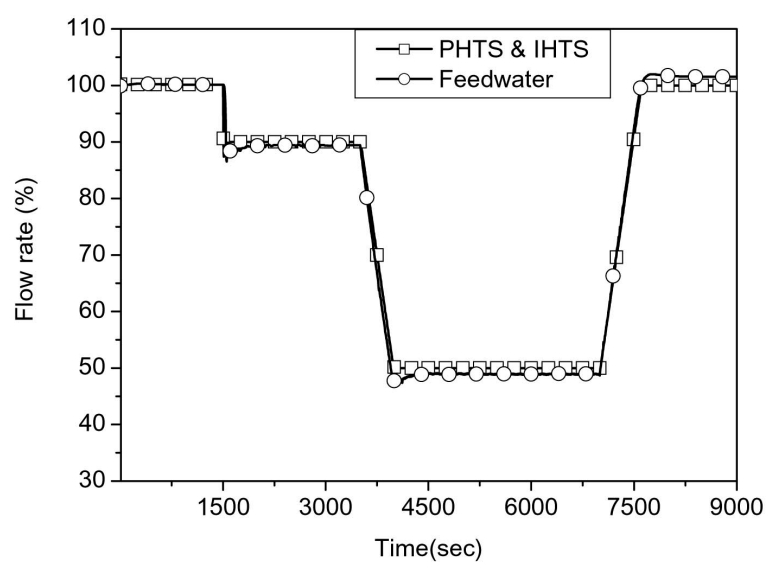

(c) flow rate
Next, we assumed that the process and set variable of the control logic was not the average temperature in the primary pool, but the power deviation between the reactor and the BOP cycle. We tested this logic with the modified logic for controlling the flow rates by simulating the same event. Figure 6 shows the simulation results and we concluded that this logic could not keep the average temperature in the primary pool constant although the reactor power closely followed the BOP power. In this logic, a new controller for the volume of the primary pool would be needed and the reactivity change in the core was larger than that in previous cases due to the change in the average temperature of the primary pool. Therefore, we concluded this control logic was not suitable for a pool-type reactor, such as the KALIMER-600.

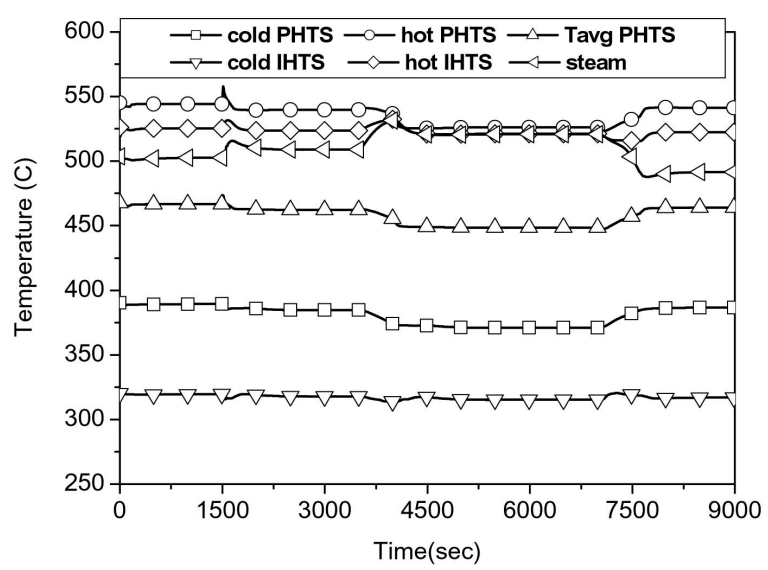

(b) temperature

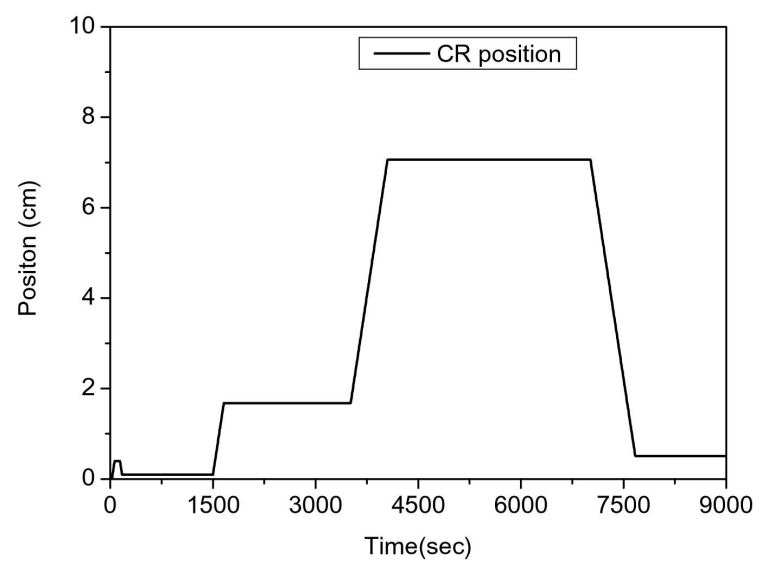

(d) control rod position

Fig. 6. Simulation Results of Case 4 
Combining the results above, we finally developed a control logic for the reactor power change. The developed logic was to keep the average temperature of the primary pool constant, and concurrently, to minimize the power deviation between the reactor and the BOP cycle[6,10]. In addition, the flow rates of the primary pool and the intermediate loop were adjusted by the level of the BOP power, not the level of the reactor power. As shown in Figure 7, the reactor power closely followed the BOP power as well as the average temperature in the primary pool was kept constant. Also, the temperature of the cold pool was able to be maintained below the creep condition. In other words, this control logic did not violate any constraints and the reactor power closely and stably followed the BOP power. Therefore, we concluded this control logic was the most promising one for the power maneuvering event of the KALIMER-600.

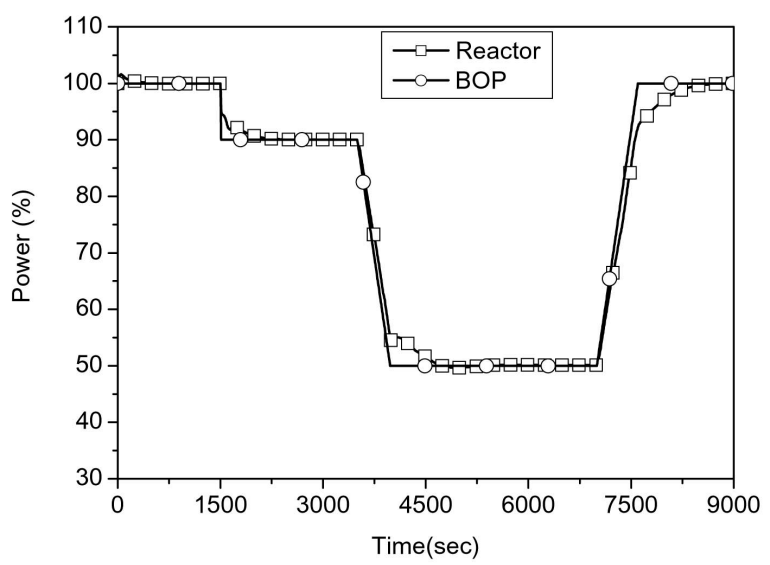

(a) power

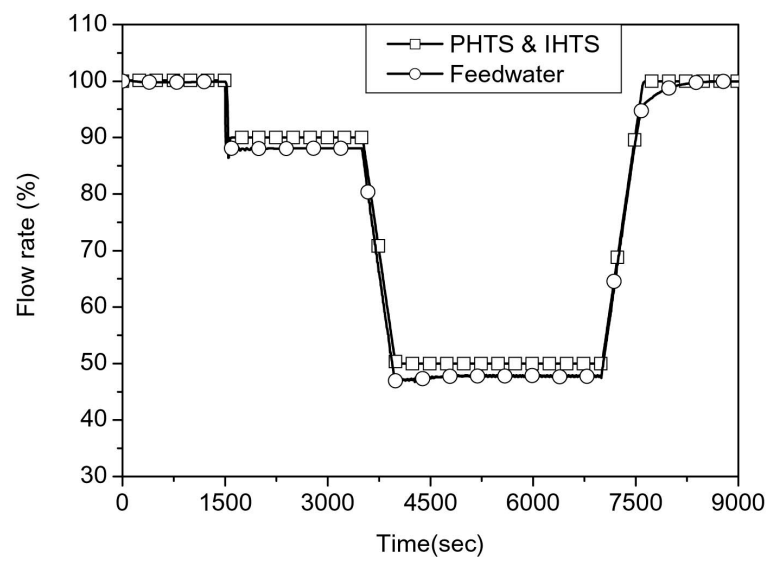

(c) flow rate
Additionally, we examined the effect of the movement speed of the control rods. The speed can affect the stabilization of the reactor power during the power maneuvering event. We assumed all control rods moved step by step and the reactivity change of the core resulted from a change in the control rod position, feedback mechanism of the coolant temperature, and the Doppler. The reactor power would oscillate during the power level change if the reactivity change from one step movement of the control rods was much larger than the sum of the other feedback. We searched for an achievable movement speed of the control rods for the power maneuvering event. In all the previous cases, we used a slow movement speed for the control rods $(0.01 \mathrm{~cm} / \mathrm{s})$ for a stable operation.

We tested some movement speed of the control rods and show two representative cases in Figures 8 and 9. We set the speed at $0.025 \mathrm{~cm} / \mathrm{s}$ for Case 6 (Figure 8) and

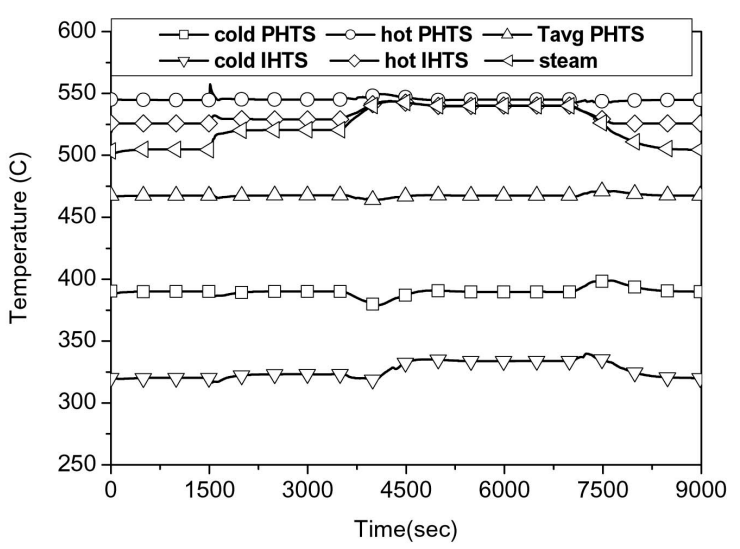

(b) temperature

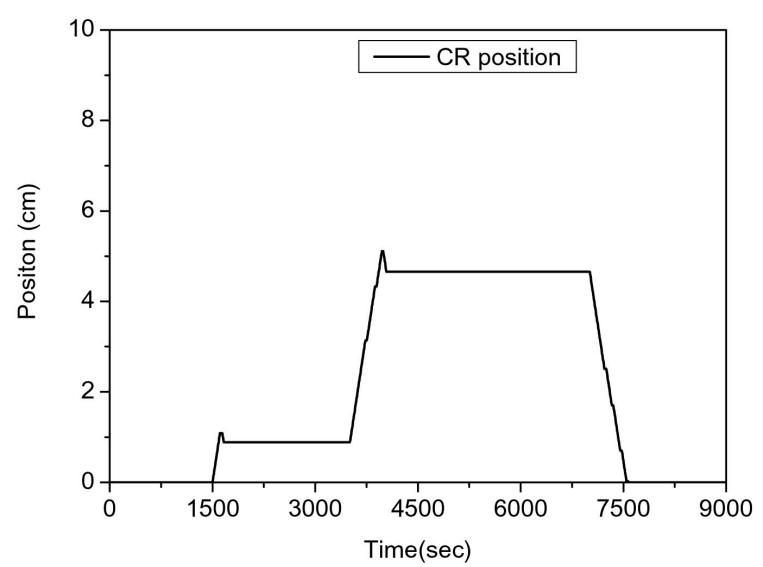

(d) control rod position

Fig. 7. Simulation Results of Case 5 
$0.035 \mathrm{~cm} / \mathrm{s}$ for Case 7 (Figure 9), respectively. From the results, we found that the position of the control rods and the reactor power fluctuated when the movement speed was $0.035 \mathrm{~cm} / \mathrm{s}$. Therefore, we found that the $0.025 \mathrm{~cm} / \mathrm{s}$ was an achievable movement speed for the control rods in a stable operation and a quick response during the power maneuvering event.

\section{CONCLUSIONS}

We examined some logics for controlling the reactor power of the KALIMER-600 and then developed a control logic for the reactor power in a power maneuvering event. We concluded that keeping the average temperature of the primary pool constant and concurrently minimizing the deviation between the reactor power and the BOP

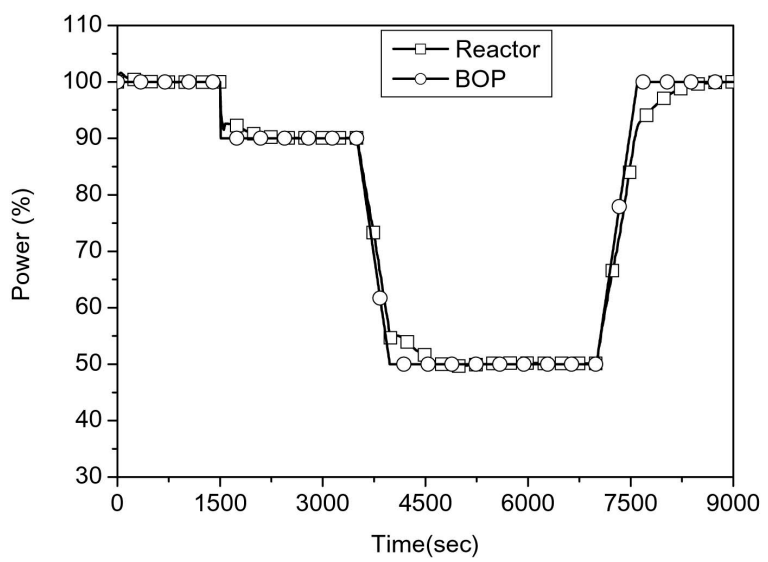

(a) power

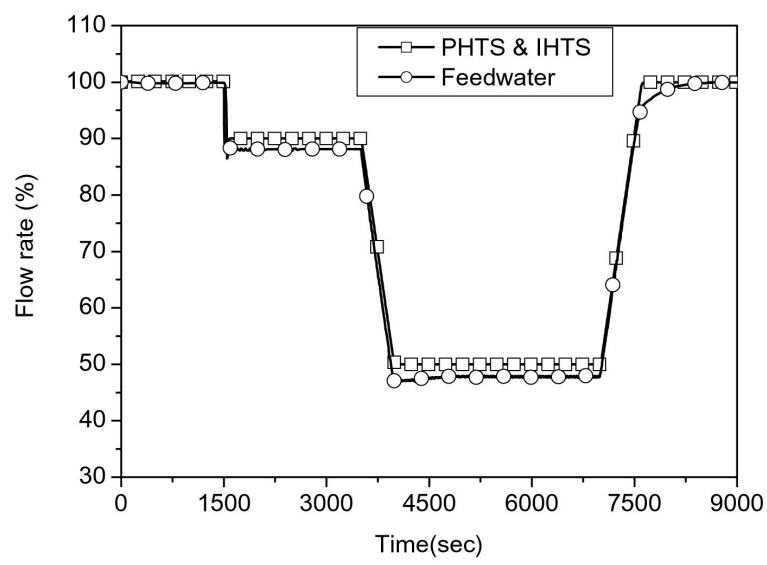

(c) flow rate power was a reasonable logic for the reactor power control. Also, the variable flow rates of the primary pool and the intermediate loop according to the power level was acceptable in controlling the average temperature of the primary pool and in keeping the cold pool temperature less than the creep condition of the reactor vessel during plant operation. In addition, we searched for an achievable movement speed for the control rods during the power maneuvering event. With the developed control logics, the reactor power asymptotically and stably followed the BOP power with no constraints set up in this study being violated during the power maneuvering event. However, when the suggested logic was employed, it seemed to take a long time for the reactor power to follow the BOP power because of the small fluctuations that occurred from the variable flow rates. In further studies, we will optimize the control logic that can eliminate the fluctuations of the

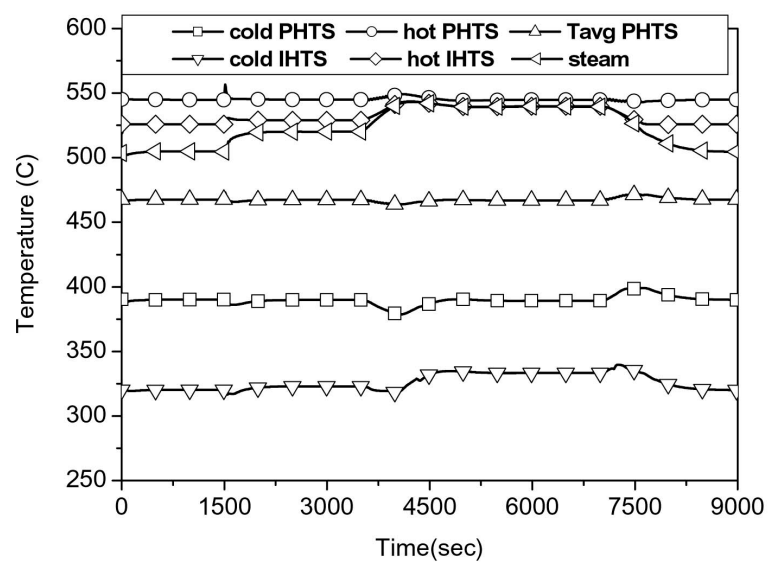

(b) temperature

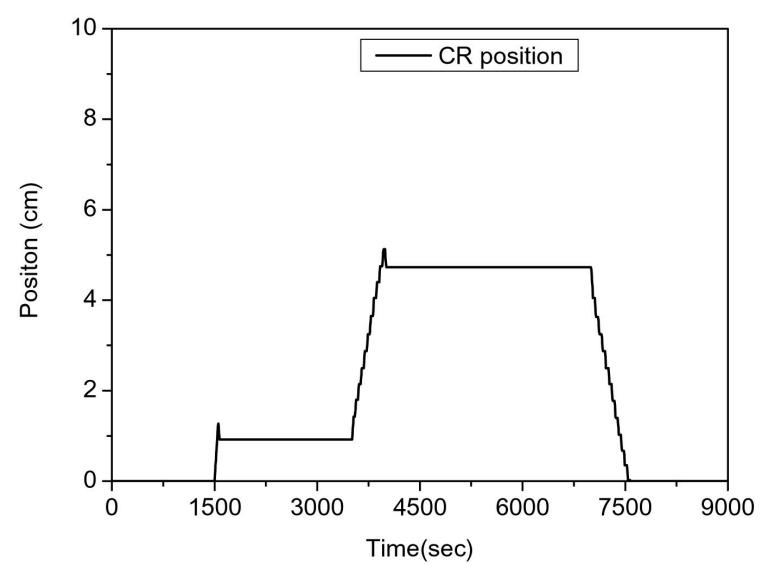

(d) control rod position

Fig. 8. Simulation Results of Case 6 


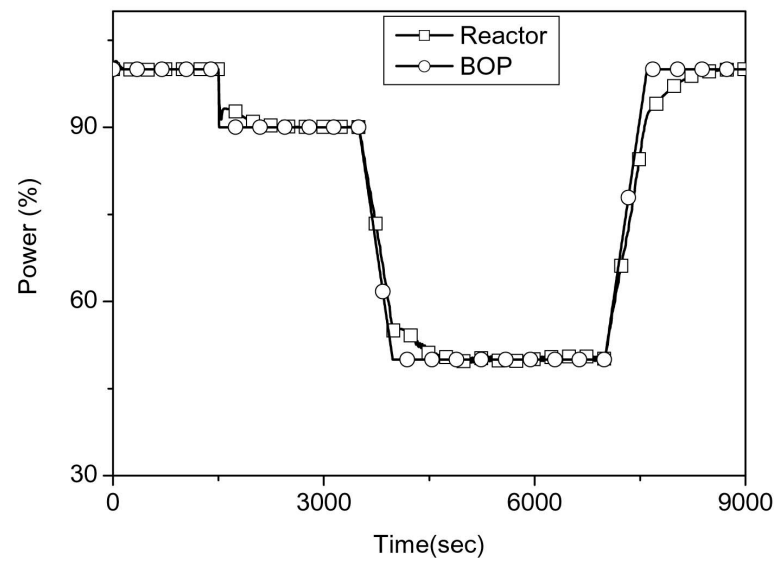

(a) power

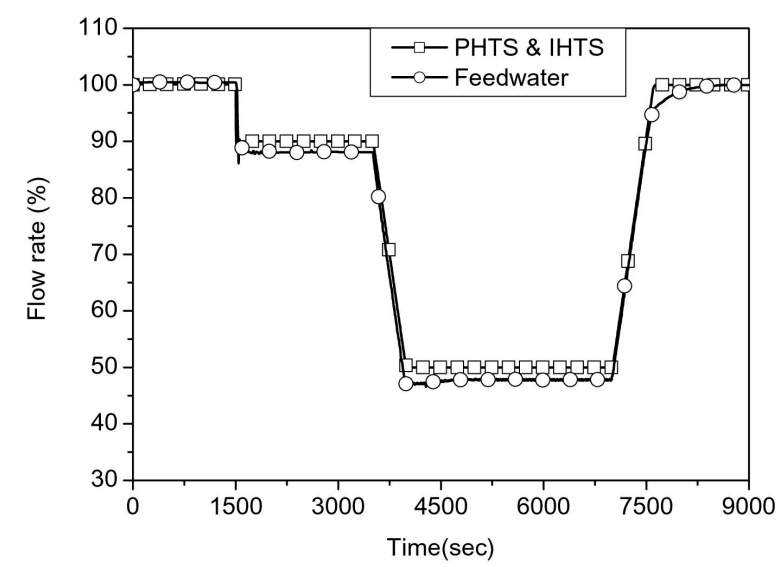

(c) flow rate

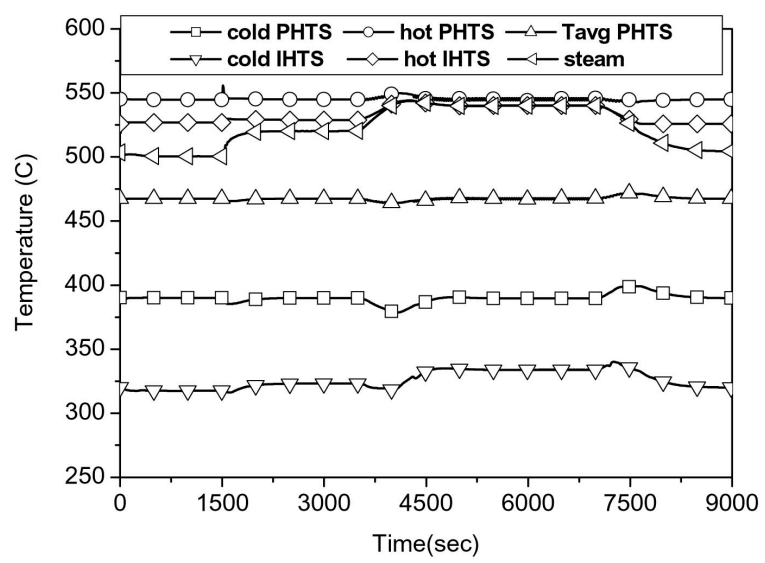

(b) temperature

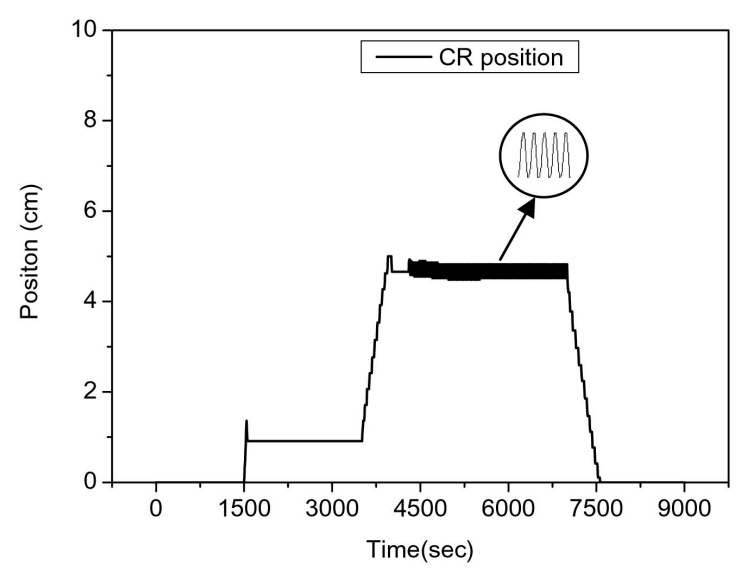

(d) control rod position

Fig. 9. Simulation Results of Case 7

reactor power and minimize the control complexity of the BOP cycle during the power maneuvering.

\section{REFERENCES}

[1] Hahn D.H. et al., KALIMER-600 Conceptual Design Report, KAERI/TR-3381 (2007)

[2] Seong S.H. et al, Development of a Simplified Model for Analyzing the Performance of KALIMER-600 Coupled with a Supercritical Carbon Dioxide Brayton Energy Conversion Cycle, Nucl. Eng. and Tech., pp 785-796, Vol. 41 No.6 (2009)

[ 3 ] nHance, MMS Basics, nHance Technology, Inc. (2007)

[4] ANL, Thermodynamic properties of sodium, ANL-CENRSD-79-1, (1979)
[ 5 ] Ha, K.S., Jeong J.Y. and Hahn D.H., Simulation of EBRII SHRT-17 test using MARS code, NUTHOS-7, Seoul, KOREA, 5-9, Oct. (2008)

[ 6 ] Kang H.O. and Park C.T., Option Study on a Steam Pressure Control Logic for SMART, ICONE16, Orlando, USA (2008)

[ 7 ] Rao P.R.V, et al., Annual report of Indira Gandhi Centre for Atomic Research (2008)

[8] Chang L.K. et al., Demonstrations of EBR-II Power Maneuvers without Control Rods Movement, Nucl. Eng. and Des., pp141-148, Vol. 113 (1989)

[ 9 ] IAEA-TECDOC-1531, Fast Reactor Database 2006 Update (2006)

[10] Na M.G, Hwang I.J and Lee Y.J, Design of a Fuzzy Model Predictive Power Controller for Pressurized Water Reactors, IEEE trans. on Nucl. Sci., Vol. 53, No. 3, (2006) 